\title{
¿GÓTICO VERSUS RENACIMIENTO? UNA APROXIMACIÓN A LA ORNAMENTACIÓN "A LA ROMANA" EN EL REINO DE VALENCIA: ca. 1447-1564*
}

GOTHIC VERSUS RENAISSANCE? AN APPROACH TO THE ORNAMENTATION "A LA ROMANA" IN THE KINGDOM OF VALENCIA: ca. 1447-1564

\author{
ALBERT FERRER ORTS ${ }^{\star *}$, ESTEFANIA FERRER DEL RÍO ${ }^{* * *}$ \\ JOSEP-MARÍ GÓMEZ I LOZANO****
}

Resumen: Los objetivos de este trabajo son ponderar la importancia de la decoración "a la romana" en la introducción del renacimiento italiano en el reino de Valencia entre los siglos XV-XVI y poner en valor el rol que desempeñaron la llegada de artistas transalpinos, y la importación de esculturas y lapidaria latina, evidencias que fueron condicionando la plástica de los talleres valencianos, hasta entonces mediatizados por la estética gótico-flamenca. Se aborda la importancia del humanismo, con Vives a la cabeza, nacido con la Universitat de València, como dinamo cultural atractivo para la nobleza, pues todo ello explicará las novedades artísticas que se suceden en la catedral de Valencia o el surgimiento de un pintor excepcional como Joan de Joanes. No obstante, la aristocracia se identificó tardíamente con el renacimiento, aunque se familiarizó con el humanismo, al contrario de la jerarquía eclesiástica, pues no fue fácil su aceptación en una sociedad cuya mentalidad era todavía medieval. Ofrecemos una nueva lectura de la llegada del lenguaje arqueológico y su impacto en el arte valenciano, vía de entrada del renacimiento a España gracias al contacto privilegiado de Valencia con Italia.

Palabras Clave: Gótico, renacimiento, humanismo, ornamentación clásica, reino de Valencia.

Aвstract: The objectives of this work are to weigh the importance of the decoration "a la romana" in the introduction of the Italian Renaissance in the kingdom of Valencia between the XV-XVI centuries and to value the role that the arrival of transalpine artists played, the import of sculptures and Latin lapidary; evidences that were conditioning the visual arts of the Valencian workshops, until then mediated by the Gothic-

\footnotetext{
* Este artículo se inscribe en el proyecto de investigación I+D: "Memoria, imagen y conflicto en el arte y la arquitectura del Renacimiento: la Revuelta de las Germanías de Valencia” (HAR2017-88707-P), financiado por el Ministerio de Ciencia, Industria e Innovación y la Agencia Estatal de Investigación, Gobierno de España.

** Doctor en Geografía e Historia. Académico de la Universitat de València, Valencia, España. Correo electrónico: albert.ferrer-orts@uv.es. Orcid: https://orcid.org/0000-0001-8230-1330

*** Doctora en Geografía e Historia. Académica de la Universitat de València, Valencia, España. Correo electrónico: estefaniaferrerdelrio@gmail.com. Orcid: https://orcid.org/0000-0001-5712-8521

**** Doctor en Bellas Artes. Académico del IES Instituto Lluís Vives, Valencia, España. Correo electrónico: josepgomezl@yahoo.es. Orcid: https://orcid.org/0000-0003-0169-6444
} 
Flemish aesthetic. The importance of humanism is addressed, with Vives at the head, born with the University of Valencia, as an attractive cultural dynamo for the nobility, since all this will explain the artistic novelties that occur in the Cathedral of Valencia or the emergence of an exceptional painter like Joan de Joanes. However, the aristocracy was belatedly identified with the Renaissance, although it did so with humanism, unlike the ecclesiastical hierarchy, since it was not easy to accept it in a society whose mentality was still medieval. We offer a new reading of the arrival of the archaeological language and its impact on Valencian art, the Renaissance entry way to Spain thanks to Valencia's privileged contact with Italy.

KeYwords: Gothic, Renaissance, humanism, classic ornamentation, kingdom of Valencia

Recibido: 02.04.2019. Aceptado: 04.08.2020.

LA HORA DE ENCARAR este trabajo nos vinieron a la mente, casi de
forma instantánea, los estudios que desde la órbita de la historia del
arte valenciano se le han dedicado tanto a las manifestaciones artísticas de
la Baja Edad Media como a las que, supuestamente, las sucedieron en la aún
incipiente Edad Moderna en un alarde de modernidad más o menos coin-
cidente con lo que venía ocurriendo en otras geografías hispanas, siempre a
remolque de lo que acontecía en Italia, Flandes o Francia (Benito y Bérchez,
1982; Pérez, 1985, pp. 172-273; Llobregat e Yvars, 1986 y 1988; Aguilera,
1987a, 1987b y 1989; Company, 1987, 1990, 1991 y 2006; Bérchez y Jarque,
1994; Falomir, 1994 y 1996; Gracia, 1995, pp. 129-228; Garín, 1999, pp.
5-100; Gómez-Ferrer, 2000, pp. 151-170; Hernández, 2006; Gómez-Ferrer
y Zaragozá, 2008, pp. 149-184).
En realidad, ambas nomenclaturas de carácter histórico para explicar
sendos períodos artísticos (gótico y renacimiento) en el ámbito valencia-
no, como los años en los que uno y otro cohabitaron armónicamente bajo
los adjetivos de gótico flamígero, gótico mudéjar, hispano-flamenco, proto-
renacimiento, renacimiento e incluso manierismo, se nos antojan un tanto
forzadas, como se viene señalando en las últimas décadas en textos tan su-
gerentes y bien trabados como necesariamente generalistas que han venido
tratando los derroteros por los que transcurre el arte español de los siglos
XV y XVI (Marías, 1989; Checa, 1993; Nieto et al., 1997).
Si es cierto que en el contexto histórico nada acaba y nada surge de
súbito, no lo es menos que - de forma análoga- suceda lo propio con las
expresiones artísticas a que determinados acontecimientos dan lugar tras
compleja incubación y gestación. De hecho, estas circunstancias llevan a
largas etapas en las que determinadas corrientes y estilos conviven sin que 
dicha confluencia, digamos natural, pueda ser fácilmente clasificada y catalogada consecuentemente a beneficio de inventario (Marías, 1989, pp. 33 y ss.; Falomir, 1996, pp. 441 y ss.).

Sin embargo, el peso específico del estudio y enfoque historiográfico de las llamadas artes mayores (arquitectura, pintura y escultura) sigue condicionado sobremanera al análisis del fruto maduro de encrucijadas en las que la ornamentación -englobada en las denominadas artes decorativasjugó un papel fundamental (Falomir, 1996, pp. 441-471; Ferrer, 2014, pp. 33-51), dando respuesta más o menos inmediata a los anhelos renovadores de una clientela ávida de cambios, al menos de detalle, a los que el colectivo artístico debía dar una solución convincente, a pesar del peso de la tradición y de su prestigio social (Falomir, 1996, pp. 419-440; Gómez-Ferrer, 2000, pp. 151-170; y 2009, pp. 197-216; Gómez-Ferrer y Zaragozá, 2008, pp. 149-184.

Hasta el momento, muchas de las interpretaciones que se han venido ofreciendo a fenómenos como el que nos ocupa en estas páginas han apelado a los ambientes y cenáculos humanistas como motor de renovación cultural, mental y consiguientemente plástica (Marías, 1989). Un campo tan prolijo como, en demasiadas ocasiones, tomado de prestado sin apenas incidir en lo que grosso modo supuso para las élites que vieron en sus propuestas, avances y reajustes una justificación a sus acciones y poder: en definitiva, una oportunidad para perpetuar su memoria y legado para las futuras generaciones.

Desde este punto de vista, quienes se han ocupado del humanismo lo han hecho desde una perspectiva filológica, filosófica, pedagógica o dogmática sin apenas reparar en facetas tan interconectadas como la artística, tal como sucede con los historiadores del arte, quienes a menudo mentan sus logros sin bucear en lo que realmente supuso este movimiento intelectual para el Medievo y, como corolario, para la Edad Moderna; un estado de cosas que, en nuestra opinión, ha contribuido a formar una especie de compartimento estanco que, en líneas generales, ha cobrado sus víctimas.

Una de ellas, quizás la mayor de todas, que no la única, ha sido la decoración, al ser considerada a menudo como accesoria (a veces prescindible) $y$, de paso, postergar su originalidad, utilidad y adaptabilidad a los grandes conceptos que emanan de los espacios u objetos que la acogen (Marías, 1989, pp. 247-269), cuando está más que demostrado que la ornamentación, por su propio carácter -digamos que etéreo- ha sido la avanzadilla y hasta precursora de las grandes corrientes y estilos como de los que ahora nos ocupamos, gótico y renacimiento, en el reino de Valencia (Falomir, 
1996, pp. 441 y ss.; Gisbert, 2015, pp. 61-134; De Calvi, 2015), en un marco cronológico que abarca aproximadamente entre la creación del condado de Oliva (con lo que ello supuso para sus titulares a la hora de ampliar y remozar sus palacios, particularmente el que da sobrenombre al linaje en la comarca de la Safor) (Esteve, 1997) (Fig. 1) y la decoración de la cabecera del templo parroquial de San Martín en Valencia (Pingarrón-Esaín, 2009, pp. 319-348) (Fig. 2).

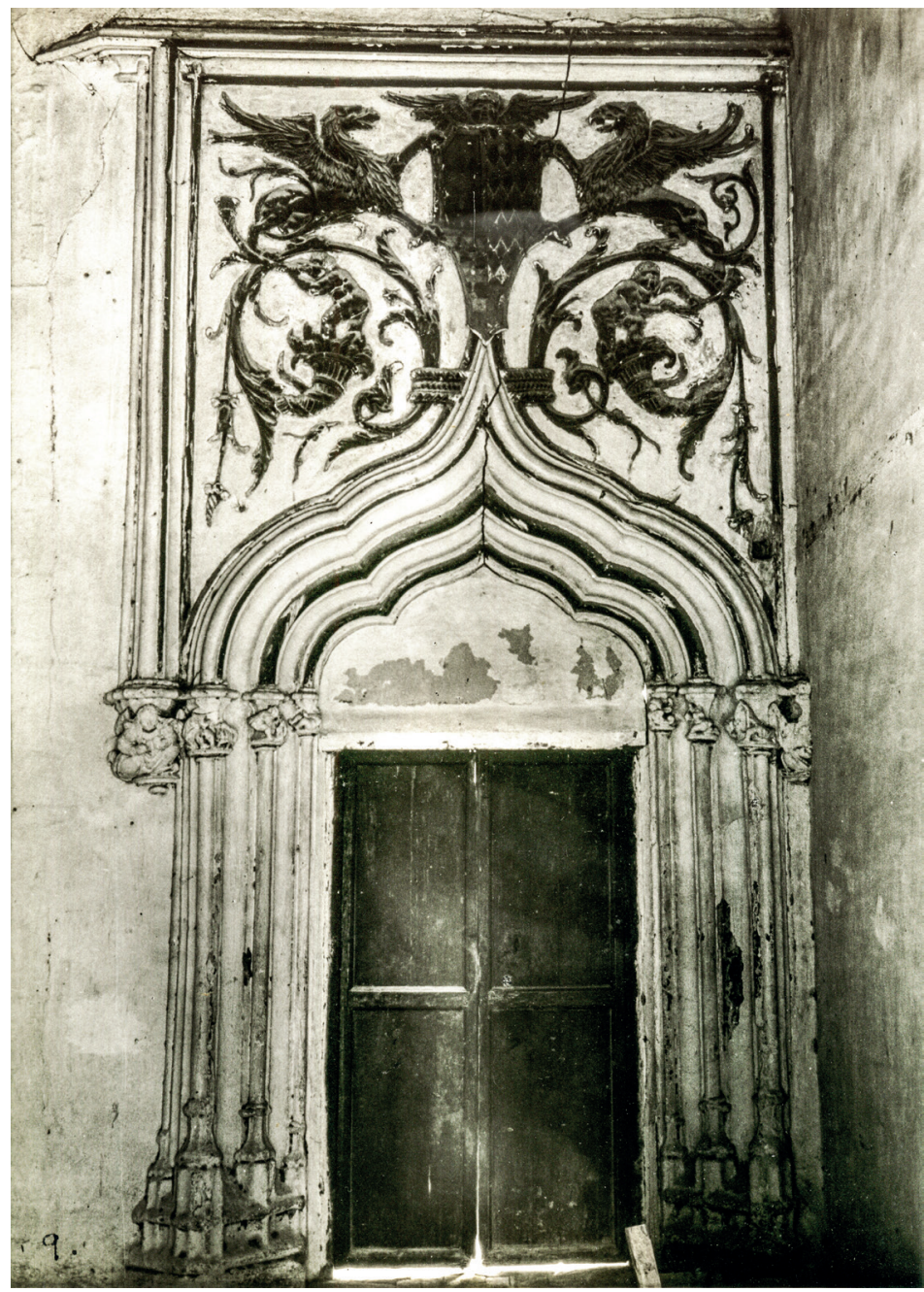

Figura 1. Retrospectiva de una portada tardo-gótica del palacio condal de Oliva (Valencia) (Ajuntament d'Oliva). 


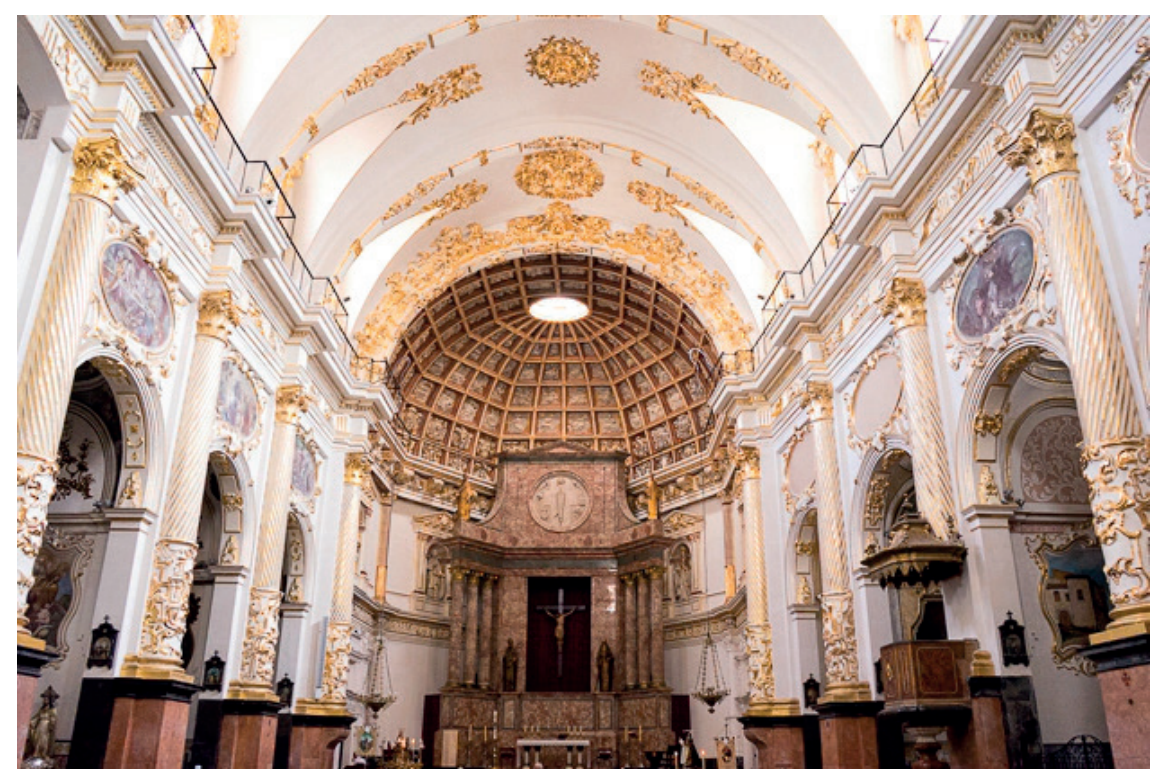

Figura 2. Cabecera renacentista de la iglesia de San Martín obispo y San Antonio abad. Valencia (LGB).

\section{UNA SOCIEDAD MEDIEVAL EN LOS ALBORES DEL SIGLO XVI}

Entre finales del siglo XV y los primeros lustros del Quinientos casi nada parece haber cambiado en la sociedad valenciana, todo parece seguir el curso natural de los años en la cotidianidad de sus habitantes e instituciones, bastante alejados unos y otras de los monarcas y sus séquitos más interesados en cuestiones tan prosaicas como las de jurar fueros, convocar Cortes y recaudar las contribuciones pecuniarias que periódicamente les demandaban (Felipo, 2004 y 2008, pp. 21-152; Callado y Valor, 2006, pp. 13-41). Sin embargo, como sucede en otras latitudes peninsulares e insulares, más si cabe en las que conforman la corona aragonesa, las consecuencias de la ambiciosa política llevada a cabo por los Reyes Católicos desde Castilla comienzan a hacerse sentir. Un período de esplendor tardomedieval que Furió (2001, pp. 159-243) acota entre 1412 y 1525.

Mientras tanto, en la capital del reino de Valencia se decora enteramente la capilla mayor de la catedral al gusto itálico -que cuenta con el temprano precedente de su primitivo trascoro-, algo semejante a lo que ocurre en la decoración de la capilla y otras dependencias de la Casa de la Ciutat (1517-1519), siguen construyéndose tanto la Llotja de la Seda (1482-1498) 
como el Consolat de Mar (1498-1548) y prosiguen las obras en el palacio de la Generalitat (1481-1585), se va remodelando el Palau del Real, extramuros de la ciudad, se instala el cortile del palacio del embajador Vich realizado en Génova (ca. 1526) (ver Fig. 3). En líneas generales, se asiste a la dicotomía entre el nuevo lenguaje importado del renacimiento italiano del Quattrocento y las más que evidentes pervivencias góticas en un paisaje urbano totalmente medieval (Falomir, 1996, pp. 473 y ss.; Benito, 2000b; Marías, 2000, pp. 25-38; Mira y Zaragozá, 2003; Pons, Muñoz y Callado, 2006; Gómez-Ferrer y Zaragozá, 2008, pp. 149-184; Serra, 2009, pp. 289 y ss; Gómez-Ferrer, 2009, pp. 197-216; García, 2011, pp. 17-70; Marín, 2014, pp. 99-110), que tendrá su contrapunto renovador en las artes supeditadas a la arquitectura como son la pintura, la escultura, la orfebrería, la tapicería o la cerámica, más porosas a la novedad por su propia naturaleza, digamos que, por lógica, subsidiaria y complementaria de aquella.

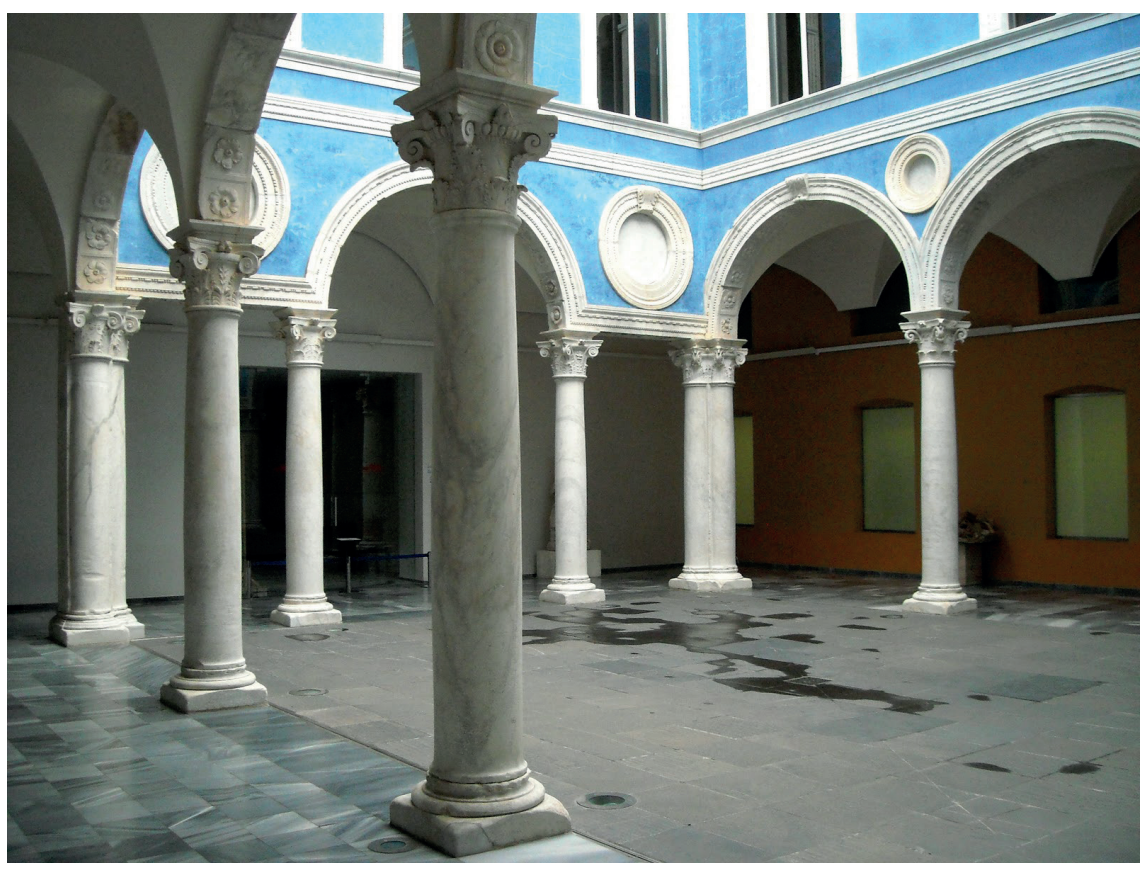

Figura 3. Cortile del palacio del embajador Vich, reconstruido en el Museo de Bellas Artes. Valencia (JG).

Un clima extrapolable a sus ciudades más importantes y sus entornos, donde sus fisonomías a través de la arquitectura civil y religiosa manifiestan 
ese apego al Medievo, excepción hecha de las decoraciones renacentistas que comienzan a tener acomodo puntual en algunos palacios, casas consistoriales, hospitales, iglesias y conventos, casos como por ejemplo los de algunas residencias nobiliarias referidas, la capilla del cardenal Francisco de Borja en la colegiata de Xàtiva, el Hospital Major de Pobres de la capital de la comarca de la Costera, algunas dependencias del monasterio de San Jerónimo de Cotalba (Alfauir), la capilla de Todos los Santos en la cartuja de Portaceli y el pórtico de la iglesia mayor de Valldecrist (Serra y Altura, respectivamente), determinados espacios del convento de Jerusalén en Valencia, las parroquiales de Andilla y Biar o las cabeceras de la catedral de Segorbe y de la ya mencionada iglesia de San Martín en Valencia.

La guerra de las Germanías (1519-1522), coincidente con sus homónimas mallorquinas y catalanas, así como con las Comunidades en Castilla, supondrá de alguna manera el fin de un ciclo de prosperidad general que perduró algo más de medio siglo y que llegó a convertir a Valencia en una de las urbes más pobladas y dinámicas de la península ibérica. Sus consecuencias coinciden con la ambiciosa política imperial de Carlos V y se asiste, desde entonces, a un lento pero progresivo declive que, sin embargo, parece no afectar al humanismo autóctono en pleno desarrollo y madurez alrededor del recientemente fundado Estudi General (Felipo, 1993). Una circunstancia análoga a lo que sucede en el plano artístico, en el que se interconectan en torno a la novedad foránea de raíz anticuaria la nobleza, la intelectualidad y los artistas.

\section{LA CAPILLA MAYOR DE LA SEO, CRISOL DEL RENACIMIENTO}

Teniendo en cuenta la precocidad con la que el lenguaje quattrocentista aparece en el coro de la catedral de Valencia, de la mano de Giulio di Nofi (o Julià lo florentí), al final del primer cuarto del siglo XV, anterior incluso que la Arcada Nova (1458-1494) que unificará definitivamente en un mismo conjunto la sala capitular y la torre del Micalet mediante estereotomía gótica, la presencia de Niccolò Delli (Nicolau lo florentî) y, posteriormente, la de Paolo da San Leocadio y Francesco Pagano para redecorar la capilla mayor entre 1472 y 1481, entre otros trabajos, son ilustrativas de la receptividad de sus canónigos y obispos hacia el arte italiano. Una sensibilidad que se incrementará sin solución de continuidad hasta el pontificado de Tomás de Villanueva (1544-1555) con sucesivas reformas como la capilla de San Luis de Tolosa (finalizada en 1486), las contrataciones de las pinturas de las puertas del retablo mayor con los Hernandos (1507-1510), entre 
otros cometidos, la realización del mencionado conjunto de plata por algunos orfebres locales y Bernabeo di Tadeo di Piero de Pone (1489-1507), el diseño y ejecución del órgano por Yáñez de la Almedina, Lluís Muñoz y Jaume Vicent (1510-1515), y, finalmente, la construcción de la capilla de la Resurrección en el trasaltar hacia 1510 con el relieve homónimo de Gregorio Bigarny (1535-1536), amén de las pinturas de Nicolau Falcó, el Maestro de Alzira o Vicent Macip, que van enriqueciendo sus paramentos hasta la colocación del portentoso "Bautismo de Cristo" de Joanes en 1535, entre otras de sus obras maestras.

Todo un alarde renovador que se enmarca en la sobriedad de la fábrica románico-gótica, pues "la catedral de Valencia fue durante el último cuarto del siglo XV y la primera década del XVI el núcleo pictórico más italianizante de la península ibérica" (Falomir, 1994, p. 86) (Fig. 4) y que compartirá, a un ritmo más lento, la élite nobiliaria en sus aposentos y obras pías, tal cual imitarán las instituciones civiles, algunos gremios, cofradías y particulares en distintas obras públicas, capillas y otros espacios religiosos.

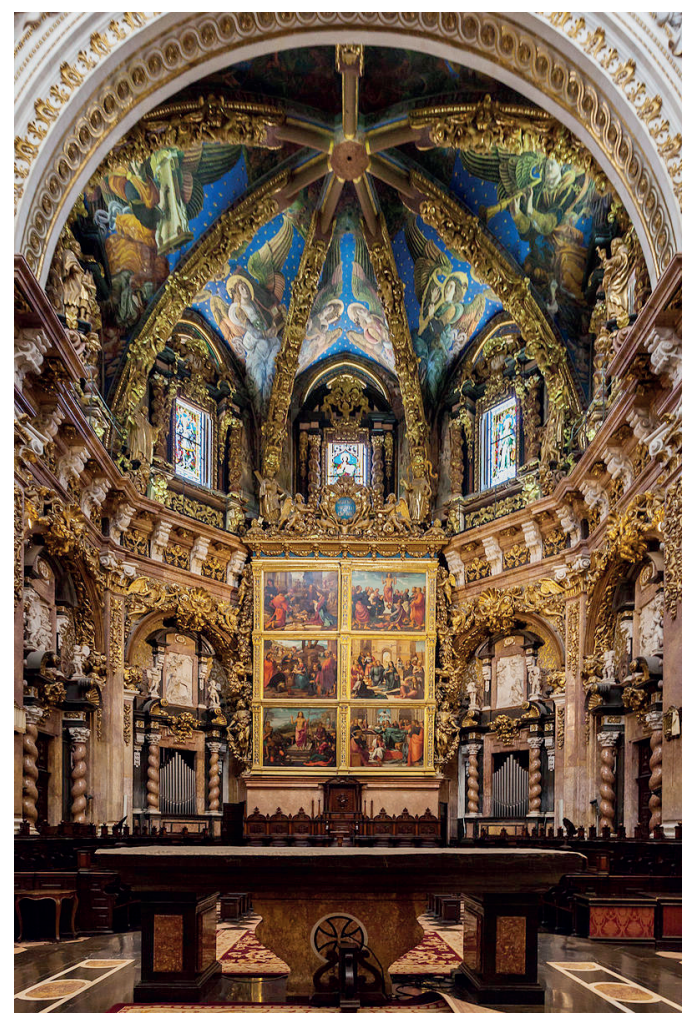

Figura 4. Capilla mayor de la catedral de Valencia (DDD). 


\section{EL HUMANISMO Y LA ARISTOCRACIA REGNÍCOLAS}

En palabras de Domingo Ynduráin (1994): "Hacia 1500, más o menos, se ha producido, se está produciendo o se va a producir un cambio profundo en todos los órdenes de la vida" (p. 383), y en ello va a jugar un papel decisivo el humanismo como contrapeso a la escolástica y a lo que esta representa como una ruptura con el saber deshumanizado o no antropomórfico, es decir, "tanto la Escolástica como el Humanismo, cada una por su lado y cada una a su manera, han establecido una suerte de aristocratismo cultural y religioso" (Ynduráin, 1994, p. 386).

El humanismo valenciano como tal se conforma a través de un nutrido grupo de eruditos nacidos desde las postrimerías del siglo XV que, de alguna manera, toma el relevo a las corrientes intelectuales precedentes (Rausell, 2001, pp. 16-29). Profesores en su mayoría del recién creado Estudi General que acogieron con inusitado entusiasmo las ideas de Erasmo de Róterdam, aunque todos no necesariamente fueran erasmistas en sus respectivas trayectorias (Pons, 2003, pp. 23 y ss.), pues

Erasmo reproduce y amplía las bases que dan origen al desarrollo de los estudios de humanidad y a la ascensión de los humanistas en la vida social y política. Así, la construcción empieza por lo más alto, por establecer la necesidad que los príncipes tienen del apoyo y asesoramiento de los humanistas. (Ynduráin, 1994, p. 427)

Además, la influencia de Joan Lluís Vives (Fig. 5), estricto coetáneo de muchos de ellos, es bien palpable gracias a su intensa correspondencia, el trasiego de libros y los viajes de algunos de ellos por tierras europeas, como han estudiado recientemente Helena Rausell y Francisco Pons, humanista que “(...) expone los peligros y problemas que causaría la comprensión y uso general e indiscriminado de esa lengua [latina], que es la que da acceso a la alta cultura: no todos deben conocer todo, hay misterios reservados que no deben ser profanados" (Ynduráin, 1994, p. 424).

Su actividad docente e intelectual en las aulas de la antigua Universitat de València como profesores de lengua latina y griega, poesía, retórica, teología, etc., se redimensionó por su cercanía a la nobleza local, al fin y al cabo el estamento que -a cambio de sus servicios pedagógicos, consejos, traducciones y literatura, a menudo panegírica- requería de su concurso merced al mecenazgo que generosamente solía dispensarles y que, en algunos casos, derivó en abierta protección y defensa debido a las pesquisas inquisitoriales. Una influencia que, en cambio, no tuvo la misma repercu- 
sión en la corte imperial, excepción hecha del propio Vives, Honorat Joan, Pere Joan Oliver, y, más tarde, con Furió Ceriol en el séquito de Felipe II (Rausell, 2001; Pons, 2003).

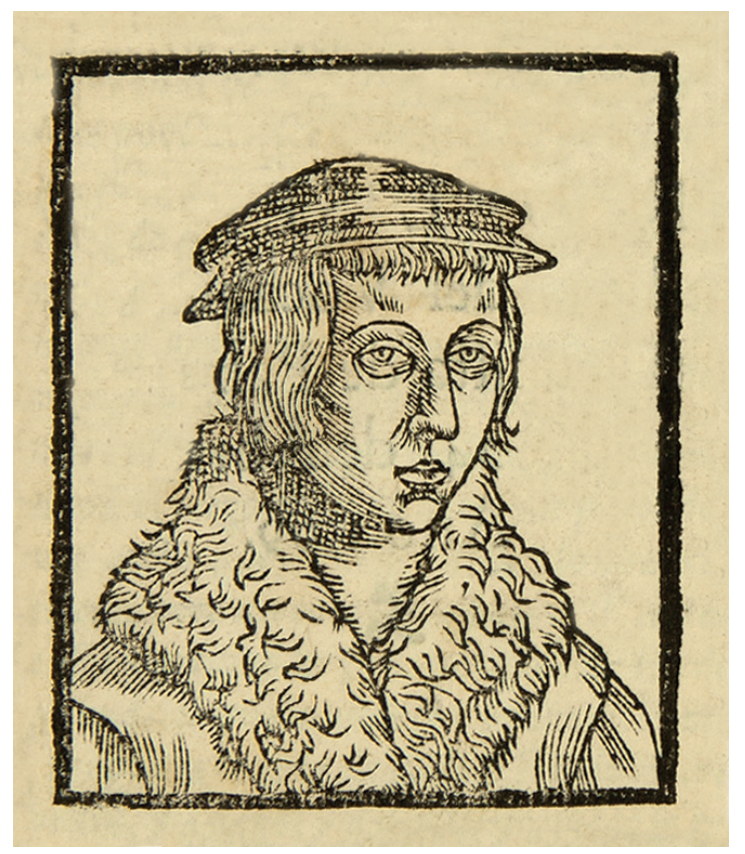

Figura 5. Xilografía con el retrato de Joan Lluís Vives (FJHD).

Algunos de estos nobles que se curtieron en numerosos cargos de responsabilidad, misiones diplomáticas y campañas militares, influenciados sin duda por su proximidad a la realidad política italiana -tan íntimamente ligada a los intereses de la Corona de Aragón- (Pons y Muñoz, 2006, pp. 43 y ss.; E. Ferrer y A. Ferrer, 2020, pp. 263-279), intentarán emular el brillo de sus exquisitos cenáculos, bibliotecas y colecciones, donde tanto los humanistas como los artistas contribuían sobremanera a cimentar su gloria y fama.

Entre ellos, cabe destacar a Francesc Gilabert de Centelles Riu-Sech i de Queralt (ca. 1408-ca. 1480), Serafí de Centelles (ca. 1460-1536) y Francesc Gilabert de Centelles Riu-Sech i Fernández de Heredia (1499-1552), los tres primeros condes de Oliva; Enrique (1445-1522) y Alfonso de Aragón (1489-1563), I y II duques de Segorbe; Fernando de Aragón (1488-1550), 
duque de Calabria -además de sus dos esposas: Germana de Foix (14881530) y, desde luego, Mencía de Mendoza (1508-1554); María Enríquez (1474-1539), Juan (1495-1543) y Francisco de Borja (1510-1572), duquesa regente, III y IV duques de Gandia, respectivamente; o el embajador Jeroni Vich (1459-1534); y Rodrigo de Mendoza (1468-1523), I marqués del Cenete. A estos cabría añadir a determinados miembros del estamento eclesiástico, culto y cosmopolita, aunque no necesariamente perteneciente a la nobleza, desde las mitras de Valencia: Gaspar de Pertusa, presbítero de San Marcelo en Roma y vicario general, el cardenal Guillem Ramon Vich o el canónigo Guillem Ramon de Centelles; Segorbe-Albarracín; el cardenal Bartomeu Martí y su sobrino Gilabert Martí; Orihuela y Tortosa; Fernando de Loazes, oriundo de Orihuela y posterior arzobispo de Valencia (Pons y Cárcel, 2005, pp. 907-950; V. Pons, 2005); hasta los cenobios de las más diversas órdenes, como los casos de los cartujos Albert Claramunt, Miquel Torres o Lluís Berenguer (Falomir, 1996, pp. 479-480; Ferrer-Gómez, 2013, pp. 233-258).

Los humanistas valencianos más destacados de esta primera mitad de la centuria que mantuvieron esta doble faceta (docente e intelectual al servicio de la aristocracia) fueron, además de Vives (1493-1540), quien cultivó la amistad de los duques de Gandia y Calabria o de Serafín de Centelles, conde de Oliva, y, particularmente, la de Carlos V. También Joan Andreu Strany (finales del s. XV-1531), canónigo, profesor de filosofía y lógica, coleccionista de antigüedades, rector del Estudi General, así como amigo de Vives y próximo al III duque de Gandia, y Joan Àngel González (ca. 14801548), profesor de poesía, cercanos ambos a Rodrigo y Mencía de Mendoza, primeros marqueses del Cenete. Pero también, en el caso de González, a Juan de Borja y Fernando de Aragón, duques de Gandia y de Calabria, respectivamente, así como Cosme Damià Savall (finales del s. XV-ca. 1532), sacerdote, profesor de griego y oratoria, discípulo de Strany y Nebrija, protegido del abad de San Marcelo Guillem Desprat y tal vez amigo de Vives y Honorat Joan; Miquel Jeroni Ledesma (ca. 1510-1547), profesor de griego; Francesc Dassió (activo en la primera mitad del s. XVI), profesor de oratoria en la órbita de Juan de Borja, duque de Gandia, y preceptor de Enrique de Borja, comendador de Montesa; Pere Antoni Beuter (1490-1554), capellán y profesor de Sagrada Escritura, quien dedicó obras al arzobispo Erardo de la Marca y a Vives, así como a las autoridades municipales. Además de Tomás Benito de Perales, profesor de gramática -cátedra denominada también "Elegàncies de Lorenç de Valla"-; Juan Justiniano (ca. 1495/1500-1556), traductor amigo de Vives; y Juan de Molina (ca. 1485-d. 
1552), traductor y escritor de novelas de caballería que elogió al marqués del Cenete, quienes formaron parte del círculo de los duques de Calabria (como del duque gandiense en el caso del segundo). Por último, se debe destacar a Bernardo Pérez de Chinchón (ca. 1488/1493-1556?), canónigo y traductor de Erasmo, del entorno más cercano al III duque de Gandia; Joan Baptista Anyés o Agnesio (1480-1553), canónigo próximo al arzobispo fray Tomás de Villanueva, escritor y preceptor de Francesc Gilabert de Centelles, conde de Oliva, además de cultivar la amistad de los duques de Gandia y Calabria, y contar con los servicios artísticos de Joan de Joanes; Honorat Joan (1507-1566), discípulo de Vives que participa del entorno del emperador Carlos, quien lo designa preceptor del príncipe Felipe y este, a su vez, antes de marchar a Inglaterra, lo nombra profesor de latín de su hijo Carlos; o Alonso de Proaza (1445-1519), profesor de retórica y secretario de Guillem Ramon de Montcada i Vilaragut, obispo de Tarazona (Rausell, 2001; F. Pons, 2003 y 2005).

Un ambiente verdaderamente favorable al cultivo del pensamiento, pues, según Rausell (2001).

No puede considerarse tardía la presencia del humanismo en el Estudi si tenemos en cuenta su cronología en las distintas universidades de la Monarquía hispánica. Además, hemos de considerar el hecho determinante de las germanías (...), [pues] todo ello viene a coincidir con el mejor momento del erasmismo hispánico. (p. 45)

\section{LETRAS, MÁRMOLES, GRUTESCOS Y PAISAJES "A LA ROMANA": LA LENTA INTRODUCCIÓN DEL LENGUAJE ARQUEOLÓGICO}

La introducción y difusión de lápidas de mármol conmemorativas en algunos de los edificios fundados por algunos nobles y eclesiásticos manifiesta que el humanismo, en su vertiente filológica, ejerció una notable atracción en estos menesteres. Así lo demuestran, por ejemplo, la fina labra de las capitales latinas utilizadas, en las que tanto Francisco de Borja en la capilla de Nuestra Señora de las Fiebres de la colegiata de Xàtiva (1497), seguido del II y III conde de Oliva en su palacio-fortaleza (de 1514 y 1546 cada una) y Dom Jeroni Alpont, prior de la cartuja de Valldecrist, para conmemorar la consagración de su iglesia mayor (1549) (Fig. 6). Pero también Lluís de Requesens, comendador mayor de la Orden de Santiago y heredero de los bienes muebles de Mencía de Mendoza, quien encargó en Génova el tú- 
mulo funerario de sus padres y la lápida de la noble para la capilla de los Reyes en el convento de Santo Domingo de Valencia (1564-1565) (Fig. 7), como los duques de Segorbe, pues de su entorno parece ser que pudieron proceder los relieves marmóreos de la "Virgen con el Niño y ángeles" (Museo Diodesano, Segorbe), atribuido a Donatello o su círculo más próximo, y la "Virgen del Loreto" (Parroquia del Salvador, Pina de Montalgrao), o Guillem Ramon de Vich, a quien perteneció seguramente el bajorrelieve del "Bautismo de Cristo" (Museo de Bellas Artes, Valencia) (Fig. 8), todo lo cual saca a colación su cercanía a la lapidaria romana y su contacto con los círculos eruditos aficionados a las antigüedades y coleccionistas de arte.

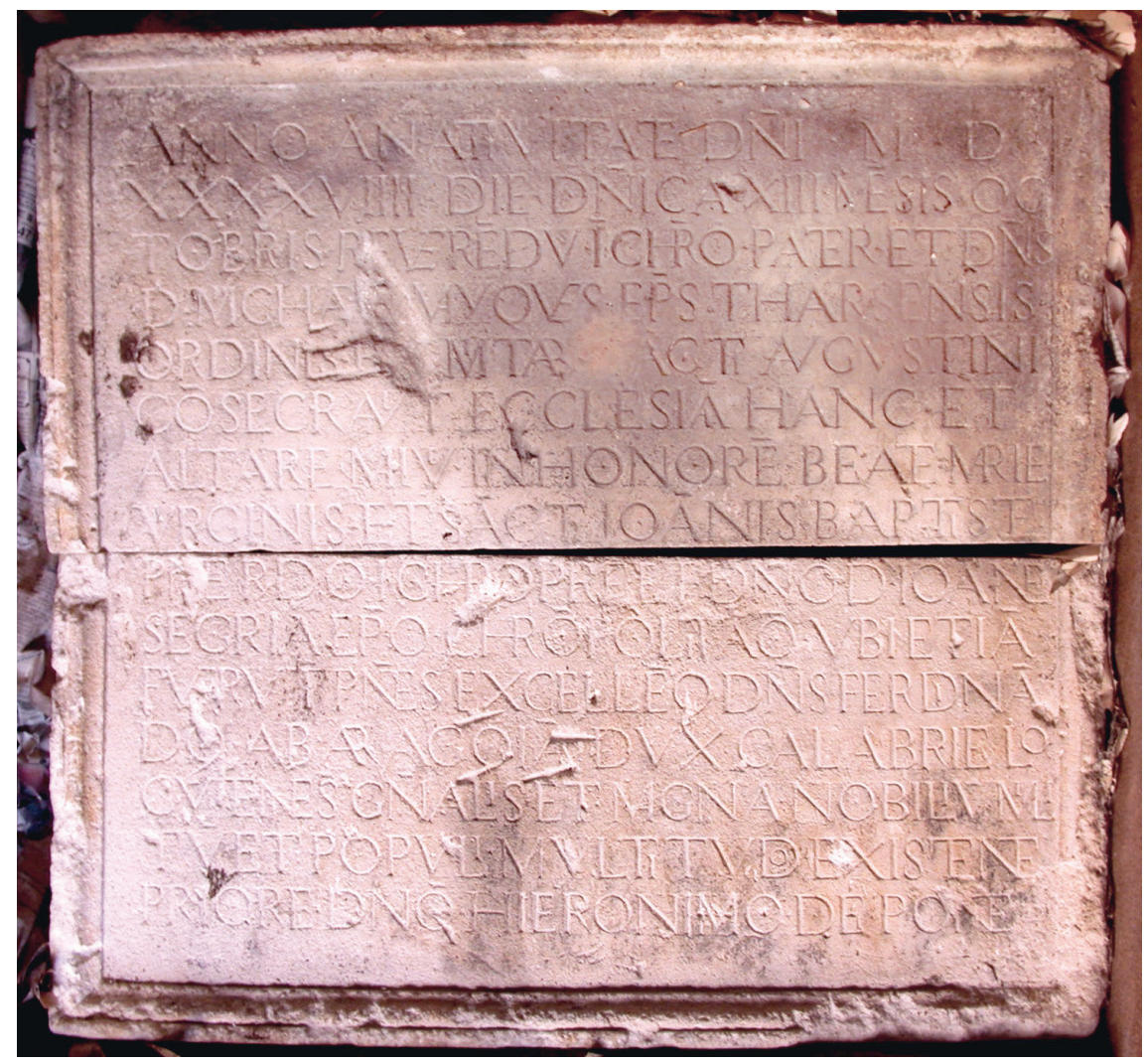

Figura 6. Inscripción conmemorativa de la consagración de la iglesia mayor de la cartuja de Valldecrist (Altura, Castellón) (JMGL). 


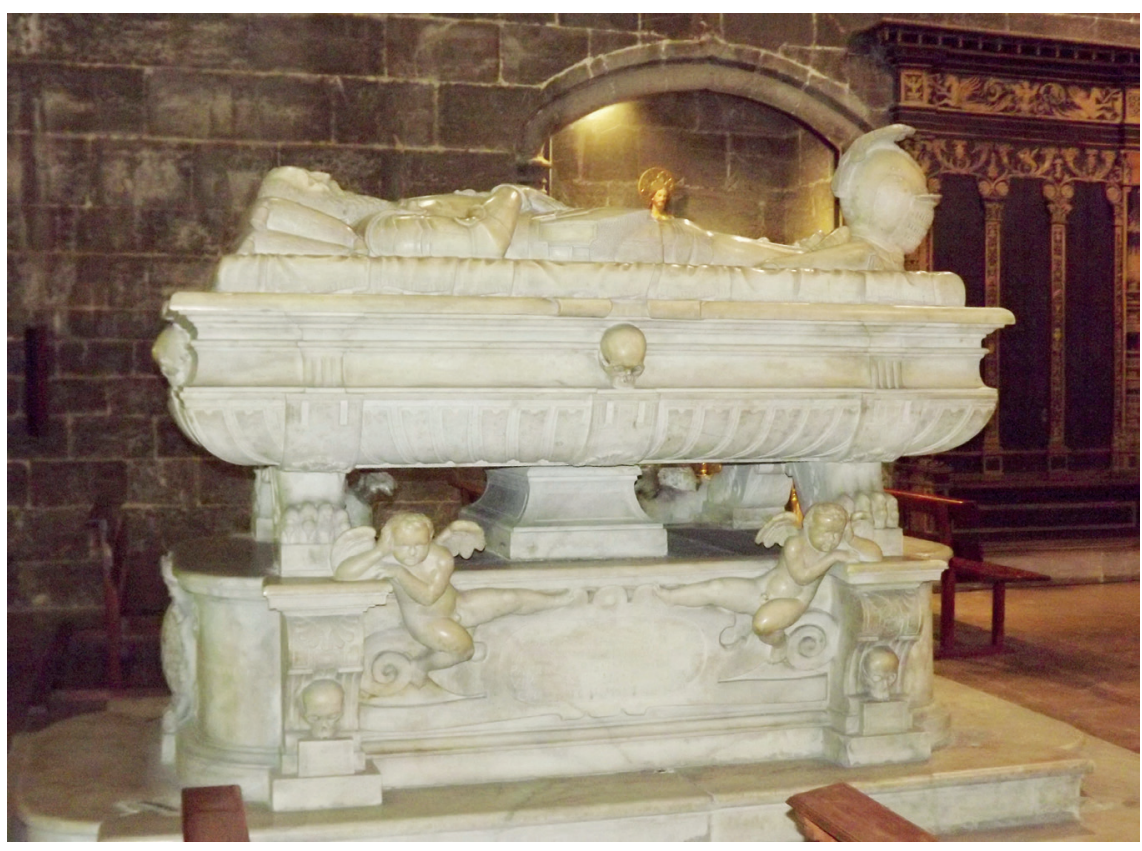

Figura 7. Castello, Carlone y Orsolino. Sepulcro de los marqueses del Cenete en el monasterio de Santo Domingo. Valencia (EFR).

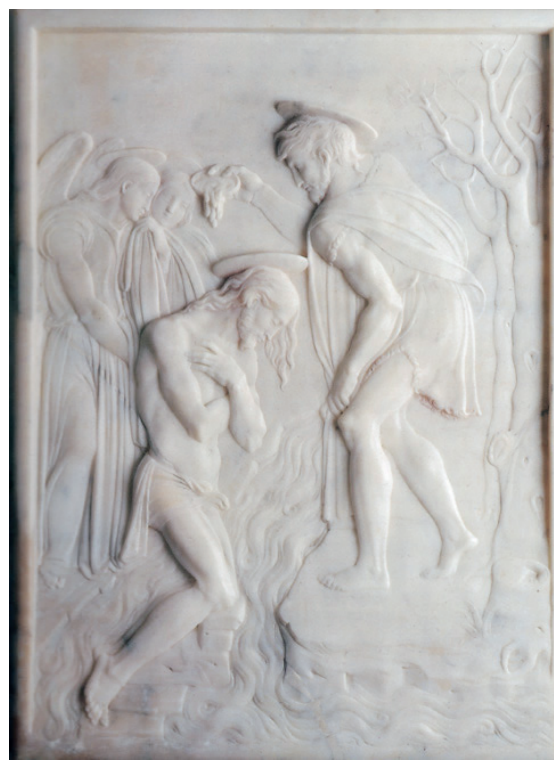

Figura 8. Anónimo italiano. Bajorrelieve con el "Bautismo de Cristo", Museo de Bellas Artes (C). Valencia. 
Un aspecto que retomarán y potenciarán a medida que avanza el Quinientos, en el ámbito pictórico, artistas como Paolo da San Leocadio, Francisco de Osona, Fernando Llanos, Yáñez de la Almedina, Miquel Esteve, el Maestro de Alzira, los Macip y, muy particularmente, Joan de Joanes, el autor que más y mejor se prodiga en los caracteres latinos y su evolución tipográfica a medida que avanza el siglo, prueba fehaciente de su proximidad al ámbito humanístico (Company, 2006; Benito y Galdón, 1997; Benito, 1998 y 2000a; Cebrián, Hernández y Navarro, 2016; Toló, 2015; Falomir, 2006, pp. 282 y ss.); como repetirán y prolongarán con desigual pericia los joanescos (Benito, 2000a; Hernández et al. 2015), detalles sobre los que se ha insistido poco desde las incursiones que efectuó el profesor Gimeno (1997, pp. 101-137, y 2005, pp. 1.519-1.564).

Por lo que se refiere a los grutescos y otras decoraciones clásicas, así como a su difusión, cabe recordar que el descubrimiento de la Domus Aurea se produjo en las postrimerías del siglo XV (Dacos, 1969; Fernández, 1979, pp. 5-20), cuyos motivos fueron copiados y reinterpretados recurrentemente por el propio Rafael y sus colaboradores, adentrándose por sus grutas, además de utilizados profusamente en la decoración de las logias vaticanas del cardenal Bibbiena.

Esto no fue óbice para que la ornamentación clásica conocida hasta entonces sirviera a numerosos creadores plásticos del Quattrocento para condimentar sus obras e imprimirles un sesgo arqueológico acorde con los tiempos. De hecho, en tierras valencianas no se observan grutescos en las pinturas al fresco desarrolladas por San Leocadio y Pagano, sí, en cambio, puntuales motivos ornamentales de inspiración grecolatina (Fig. 9). Tengamos en cuenta que cuando ambos llegan a Valencia todavía no se han descubierto las ruinas palaciegas de Nerón, circunstancia que cambiará con la aparición en 1506 de los Hernandos, pintores próximos a Lippi y Leonardo, que vivieron en Italia con posterioridad a dicho hallazgo.

Desde entonces, con la realización de las pinturas en la seo valenciana, además de los diseños elaborados para sus mazonerías alejadas del gótico, como sucedió también en el órgano, la decoración de raigambre clasicista, denominada genéricamente ya como grutesca, a candilieri o "a la romana", se popularizará entre sus colegas valencianos, retablistas, escultores y canteros, especialmente. En el caso de los maestros de obras, gracias a moldes de yeso en serie fácilmente reutilizables entre las jácenas y frisos. 


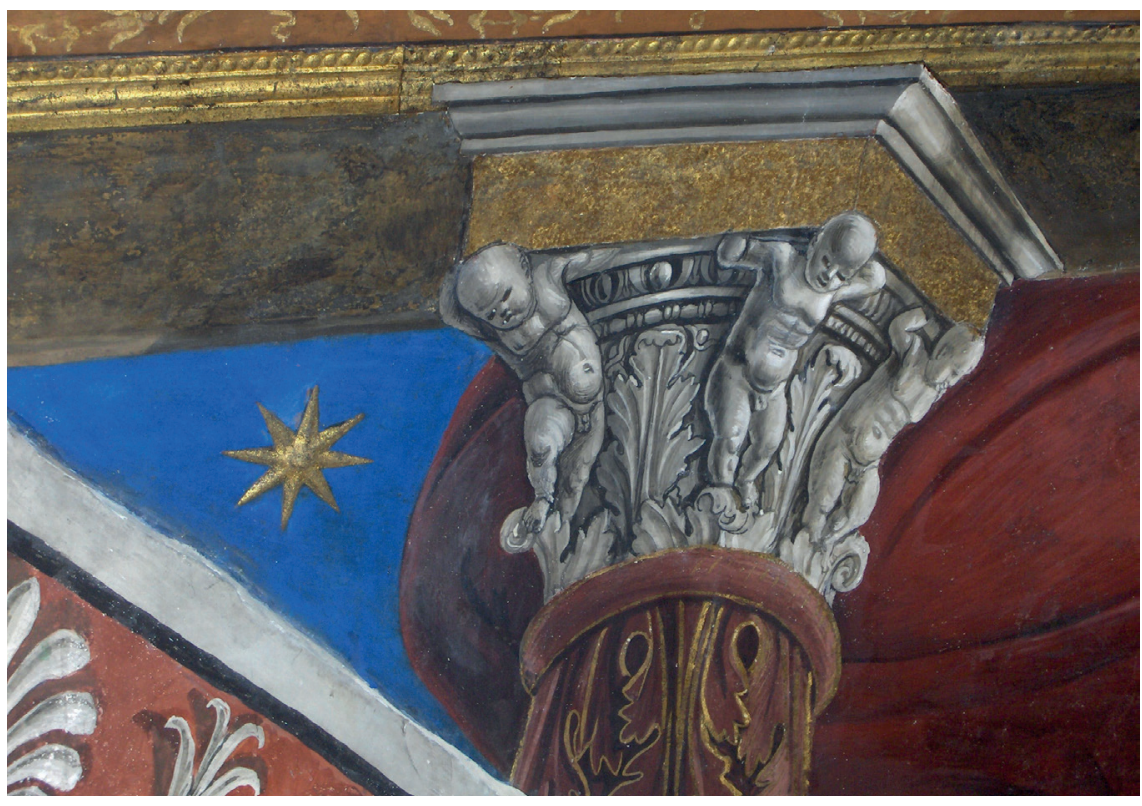

Figura 9. Paolo da San Leocadio y Francesco Pagano. Decoración clasicista en el ábside de la catedral de Valencia (CAD).

En cuanto al paisaje, en particular el arquitectónico, se evidencia un lento tránsito de representaciones ciertamente estereotipadas de semblanza nórdica en los fondos de las composiciones a severas construcciones de raigambre clásica, en ocasiones arruinadas. En este sentido, nos parece interesante reseñar las decisivas aportaciones de San Leocadio y los Hernandos, toda una novedad, los Macip, y, de entre ellos, de nuevo Joanes es quien desde mediados del siglo XVI se hace eco de los monumentos y ruinas romanas, probablemente a través de las pinturas, dibujos y estampas de flamencos italianizados que debió contemplar en la magnífica colección de Mencía de Mendoza en el Real de Valencia (Falomir, 2006, p. 278; A. Ferrer y E. Ferrer, 2016, pp. 78-95). De no haber ido Juan de Juanes a Italia, como sospechamos, no hallamos otra explicación a su continuo manejo en su madurez mediante obeliscos, pirámides funerarias, mausoleos, las ruinas de las termas de Trajano y de la Domus Aurea, el templo de San Pietro in Montorio, acueductos, etc., a veces combinados; aspectos que retomará y prolongará en sus obras Gaspar Requena, autor que suponemos se especializó, entre otros acabados secundarios, en este tipo de detalles mientras colaboró con Joanes (Benito y Galdón, 1997; Benito, 2000a; Hernández et al., 2015). En palabras de Falomir (2006): 
(...) creo que las ruinas joanescas, que aparecen sólo bien entrada la década de 1540, más que delatar inquietudes anticuarias son concesiones al gusto imperante, desempeñando un papel análogo al de las referencias a hechos y autores clásicos que pueblan las obras de escritores (...). Probablemente nada delate mejor el carácter ornamental de las ruinas que su reiteración (son siempre las mismas, procedentes de una fuente impresa por identificar) y ubicuidad. (p. 278)

Esto nos induce a pensar en la lógica presencia de obras con esta temática, debidas, por ejemplo, a Gossart, Van Schorel y Van Heemskerk (Fig. 10) en la fabulosa colección artística de Mencía de Mendoza, como ya se ha referido.

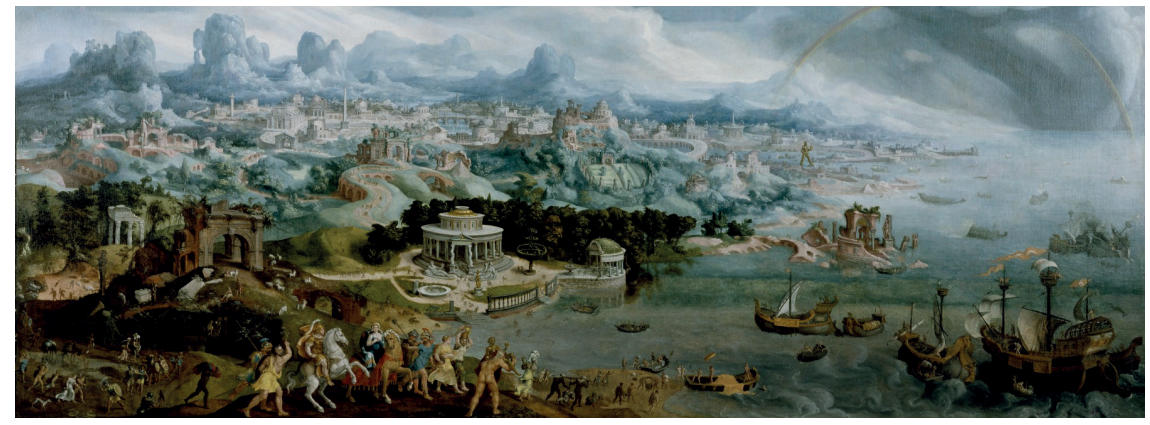

Figura 10. Maerten van Heemskerk, "Panorama con el secuestro de Helena en medio de las maravillas del mundo antiguo", The Walters Art Museum ๑. Baltimore.

\section{CONCLUSIONES}

Aunque se puede afirmar que la nobleza autóctona no se identificó con el renacimiento artístico en la misma medida que sus coetáneos italianos, no podemos decir lo mismo respecto a su aceptación del humanismo a través de un buen número de intelectuales, buenos conocedores del legado clásico y de las aportaciones de sus homólogos italianos (Petrarca, Valla, Ficino, Della Mirandola, etc.) y nórdicos (Erasmo, principalmente); un panorama cultural que tal vez dista de ser armónico o equilibrado por la fiabilidad que transmitía el gótico, las dificultades que entrañaba edificar "a la romana", la mayor versatilidad de la ornamentación de naturaleza anticuaria y, con ella, de otras artes muebles como la pintura, la escultura, la tapicería o la orfebrería (Gómez-Ferrer y Zaragozá, 2008, pp. 149-184; Gómez-Ferrer, 2009, pp. 197-216; Marín, 2014, pp. 99-110). 
En este contexto, el impulso renovador que desempeñó la diócesis de Valencia, en especial con los Borja como titulares de su mitra, tuvo sus consecuencias más afortunadas en su catedral, un espejo en el que no dejaron de mirarse tanto la aristocracia como los humanistas y los artistas, y que también ejerció de dinamo transformador de la mentalidad durante gran parte del siglo XVI. Es verdad que, en el período que proponemos, apenas contamos con edificios plenamente renacentistas (exceptuando la ciudad de Villena, entonces parte de Castilla), pero en todo caso sí que se constatan numerosas intervenciones, más o menos puntuales, como portadas pétreas y de aljez, patios de mármol y relieves importados, lápidas conmemorativas, profusas ornamentaciones pintadas o de yeso y estuco a base de moldes, artesonados (Figs. 11 y 12), retablos, órganos, sillerías, puertas, pinturas al fresco y sobre tabla o lienzo, miniaturas, tapicería u orfebrería.

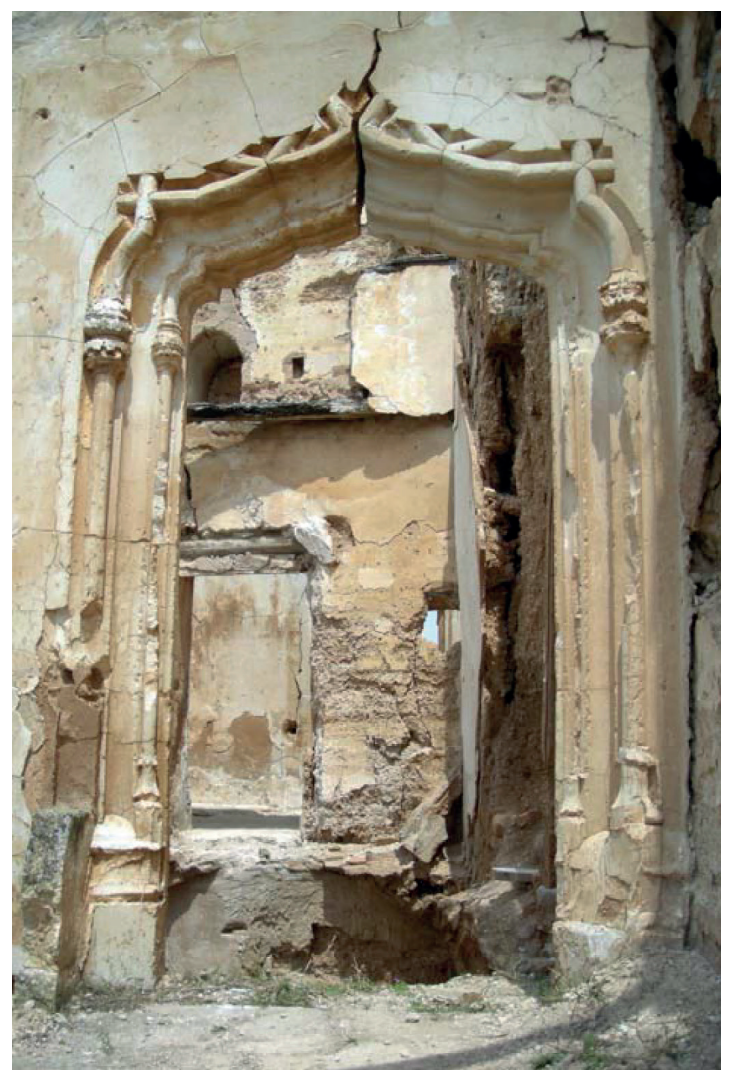

Figura 11. Puerta gótica de yeso de la escalera del patio del palacio de Bolbaite (Valencia) (RMS). 


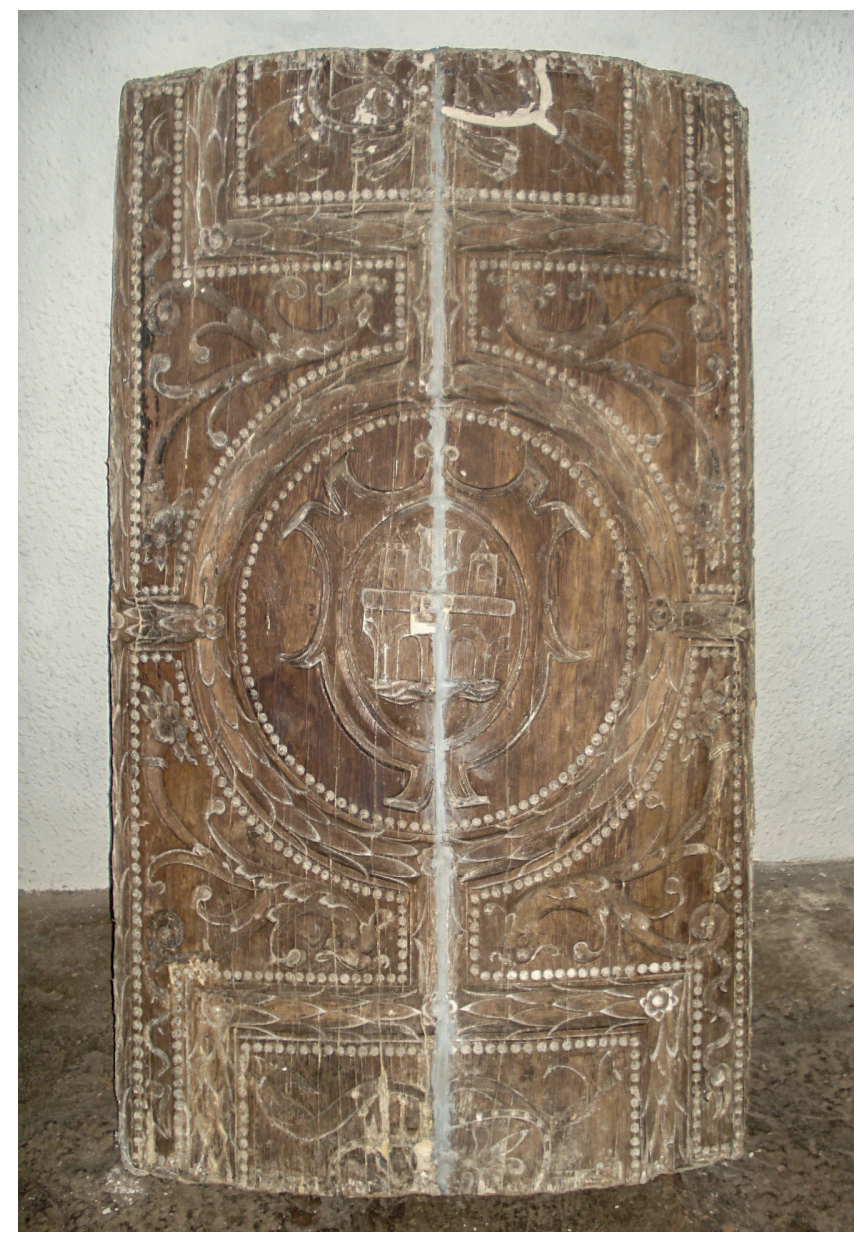

Figura 12. Molde de madera con motivos ornamentales clásicos para el artesonado de yeso de la lonja. Alpuente (Valencia) (AR).

Al fin y al cabo, el sustrato gótico local desarrollado desde el siglo XIII amparó paulatinamente la novedad transalpina, bien que incorporándola y fusionándola con sus formas y hasta conceptos, tal como acontecía desde antaño con el influjo flamenco, más afín a su idiosincrasia y estética (Benito y Gómez, 2001 y 2007); una circunstancia en la que la Iglesia fue, sin duda, la precursora de su introducción, relegando a un segundo plano a una nobleza humanista más preocupada en principio en los textos que en las artes, así como a las instituciones civiles. Solo "al iniciarse la tercera década del siglo XVI, la asunción de una insalvable diferencia entre unos viejos y unos 
nuevos tiempos había arraigado en los segmentos más cultos de la población" (Falomir, 1996, p. 493).

Por último, el fracaso en la creación de un Colegio de Pintores en 1520 (en definitiva, un gremio desgajado del de carpinteros) por los pintores de retablos, cortinas e iluminadores y doradores, nos muestra a un colectivo que apenas tributaba en comparación a otros gremios y asociaciones profesionales, y que generalmente estaba englobado en la práctica artesanal, falto además de textos teóricos que redundaran en la excelencia de sus trabajos como fruto del disegno dentro de las artes liberales, y confirma el desinterés de las autoridades y el mantenimiento de unos precios verdaderamente bajos en su producción artística, lo que conllevaba implícitamente su menoscabo respecto a otras actividades consideradas como intelectuales y consiguientemente humanistas; signo que, parcialmente, cambió después de las Germanías, coincidiendo precisamente con el auge de la intelectualidad valenciana en torno a la universidad y la nobleza (Falomir, 1994).

\section{REFERENCIAS}

Aguilera, V., dir./coord. (1987a). Història de lart valencià, tomo II. València: Consorci d'Editors Valencians.

Aguilera, V., dir./coord. (1987b). Història de l'art valencià, tomo III. València: Consorci d'Editors Valencians.

Aguilera, V., dir./coord. (1989). Història de l'art valencià, tomo IV. València: Consorci d'Editors Valencians.

Benito, F., com. (1998). Los Hernandos. Pintores hispanos del entorno del Renacimiento, Valencia: Generalitat Valenciana.

Benito, F., com. (2000a). Joan de Joanes. Una nueva visión del artista y su obra. Valencia: Generalitat Valenciana.

Benito, F., dir. (2000b). El patio del palacio del Embajador Vich. Elementos para su recuperación. Valencia: Generalitat Valenciana.

Benito, F. y Bérchez, J. (1982). Presència del Renaixement a València. Arquitectura i pintura. Valencia: Institució Alfons el Magnànim, Diputació de València.

Benito, F., Galdón, J. L., coms. (1997). Vicente Macip (h. 1475-1550). Valencia: Generalitat Valenciana.

Benito, F. y Gómez, J. (2001). La clave flamenca en los primitivos valencianos. Valencia: Generalitat Valenciana.

Benito, F. y Gómez, J. (2007). La impronta florentina y flamenca en Valencia. Pintura de los siglos XIV-XVI. Valencia: Generalitat Valenciana.

Bérchez, J. y Jarque, F. (1994). Arquitectura renaixentista valenciana (15001570). València: Bancaixa Obra Social. 
Callado, E. y Valor, P. (2006). La Valencia del Embajador Vich. En V. Pons, M. C. Muñoz, y E. Callado (coords.). L'Ambaixador Vich. L'home i el seu temps (pp. 13-41). València: Generalitat Valenciana.

Cebrián, J. L., Hernández, L., y Navarro, B. (2016). Miquel Esteve. Pintor leonardesco de Xàtiva. Xàtiva: Ulleye.

Company, X. (1987). La Pintura del Renaixement. València: Ed. Alfons el Magnànim-IVEI.

Company, X. (1990). La pintura hispanoflamenca. València: Ed. Alfons el Magnànim-IVEI.

Company, X. (1991). Lart i els artistes al País Valencià modern (1440-1600). Barcelona: Curial.

Company, X. (2006). Paolo da San Leocadio i els inicis de la pintura del Renaixement a Espanya. Gandia: CEIC Alfons el Vell.

Checa, F. (1993). Pintura y escultura del Renacimiento en España, 1450-1600. Madrid: Cátedra.

Dacos, N. (1969). La decouverté de la Domus Aurea et la formation des grotesques à la Renaissance. London: The Warburg Institute.

De Calvi, S., ed. (2015). Dibujo y ornamento: trazas y dibujos de artes decorativas entre Portugal, España, Italia, Malta y Grecia. Córdoba-Roma: Diputación de Córdoba-De Luca.

Esteve, A., dir./coord. (1997). El Palau dels Centelles d'Oliva. Recull gràfic i documental, Oliva: Associació Cultural Centelles Riu-Sech.

Falomir, M. (1994). La pintura y los pintores en la Valencia del Renacimiento (1472-1600). Valencia: Consell Valencià de Cultura.

Falomir M. (1996). Arte en Valencia (1472-1522). Valencia: Consell Valencià de Cultura.

Falomir, M. (2006). Joanes y su entorno: relaciones sociales y afinidades culturales. En L. Hernández (coord.), De pintura valenciana (1400-1600). Estudios y documentación (pp. 271-287). Alicante: Instituto Alicantino de Cultura Juan Gil-Albert.

Felipo, A. (1993). La Universidad de Valencia durante el siglo XVI (1499-1611). Valencia: Universitat de València.

Felipo, A. (2004). Autoritarismo monárquico y reacción municipal. Valencia: Universitat de València.

Felipo, A. (2008). Las arcas de la ciudad. Gestión municipal e intervencionismo real en Valencia (1517-1707). Valencia: Universitat de València.

Fernández, J. (1979). La decoración grutesca. Análisis de una forma. D’Art, 5, 5-20.

Ferrer, A. (2014). La ornamentación clásica en la creación artística: el grutesco en España. Argos 31(60-61), 33-51.

Ferrer, A. y Ferrer, E. (2016). Influencias flamencas en la obra de Joan de Joanes a través de las colecciones de Mencía de Mendoza. De Arte, 15, 78-95.

Ferrer, E. y Ferrer, A. (2020. El tercer viaje a Italia de Rodrigo de Mendoza, I marqués del Cenete. Chronica Nova, 46, 263-279. 
Ferrer, A. y Gómez, J. M. (2013). Concomitancias entre el atrio de la iglesia mayor de la cartuja de Valldecrist y el tigurio del altar de la basílica de San Pedro de Roma. En S. Excoffon (ed.). Les chartreux et les élites, XIIè-XVIIIè siècles (pp. 233-258). Saint-Étienne: CERCOR-Analecta Cartusiana.

Furió, A. (2001). Història del País Valencià. València: Tres i Quatre.

García, J. V. (2011). Art i societat a la València medieval. Catarroja-Barcelona: Afers.

Garín, F. V., dir. (1999). Grandes pintores de la Comunidad Valenciana. Pasión por la luz (pp. 5-88). Valencia: El Mundo-Gules.

Gimeno, F. M. (1997). '[...] E féu vot de ell scriure lo seu nom en les portes de la ciutat'. Mensajes en catalán en las filacterias de la pintura bajomedieval. En C. Ciociola (cur.). "Visibili parlare". Le scritture esposte nei volgari italiani dal Medioevo al Rinascimento (pp. 101-133). Napoli: Edizioni Scientifiche Italiane.

Gimeno, F. M. (2005). De la 'luxurians littera' a la 'castigata et clara'. Del orden gráfico medieval al humanístico (siglos XV-XVI). Actes del X Congrés internacional d'Història de la Corona d'Aragó: La Mediterrània de la Corona d'Aragó, segles XIII-XVI \& VII centenari de la Sentència Arbitral de Torrellas, 1304-2004 (pp. 1.519-1.564), vol. II. València: Universitat de ValènciaFundació Jaume II el Just.

Gisbert, J. A. (2015). Renaixement en algeps des de Santa Maria Magdalena de Montsant -Xàtiva-. Desig i realitat alla romana de baixa gama. En B. Navarro (ed.). Notes i pinzellades al voltant de Xàtiva (pp. 61-134). Xàtiva: Ulleye.

Gómez-Ferrer, M. (2000). Artistas viajeros entre Valencia e Italia, 1450-1550. Saitabi, 50, 151-170.

Gómez-Ferrer, M. (2009). El cardenal Guillem Ramón de Vich y las relaciones entre Roma y Valencia a comienzos del siglo XVI. En F. Lemerle, Y. Pauwels, G. Toscano (dirs.). Les Cardinaux de la Renaissance et la modernité artistique. Villeneuve d'Ascq, La France: IRHiS-Institut de Recherches Historiques du Septentrion (Histoire et littérature de l'Europe du Nord-Ouest, 40), 197-216.

Gómez-Ferrer, M. y Zaragozá, A. (2008). Lenguajes, fábricas y oficios en la arquitectura valenciana entre la Edad Media y la Edad Moderna (1450-1550). Artigrama, 23, 149-184.

Gracia, C. (1995). Història de l’art valencià. València: Institució Alfons el Magnànim-IVEI.

Hernández, L., coord. (2006). De pintura valenciana (1400-1600). Estudios y documentación. Alicante: Instituto Alicantino de Cultura Juan Gil-Albert, Diputación de Alicante.

Hernández, L., Ferrer, A., Gómez, J.-M., López, M. J. (2015). Gaspar Requena, pintor valenciano del Renacimiento (c. 1515-después de 1585). Xàtiva: Ulleye.

Llobregat, E. A., e Yvars, J. F., coords. (1986). Història de l’art al País Valencià, vol. I. València: Tres i Quatre. 
Llobregat, E. A., e Yvars, J. F., coords. (1988). Història de l’art al País Valencià, vol. II. València: Tres i Quatre.

Marías, F. (1989). El largo siglo XVI. Los usos artísticos del renacimiento español. Madrid: Taurus.

Marías, F. (2000). La arquitectura de la ciudad de Valencia en la encrucijada del siglo XV: Lo moderno, lo antiguo y lo romano. Anuario del Departamento de Historia y Teoría del Arte (UAM), XII, 25-38.

Marín, R. (2014). Uso estructural de prefabricados de yeso en la arquitectura valenciana de los siglos XV y XVI, tesis doctoral. Valencia: Escuela Técnica Superior de Arquitectura, Universitat Politècnica de València.

Mira, E. y Zaragozá, A., eds. (2003). Una arquitectura gótica mediterránea, 2 vols. Valencia: Generalitat Valenciana.

Nieto, V., Morales, A. J., y Checa, F. (1997). Arquitectura del Renacimiento en España, 1488-1599. Madrid: Cátedra.

Pérez, A. E. (1985). Arte. En J. M. De Azcárate (comp.). Tierras de España (pp. 172-273): Valencia. Madrid: Fundación Juan Mach-Noguer.

Pingarrón-Esaín, F. (2009). La iglesia parroquial de San Martín obispo y San Antonio Abad de Valencia. En F. V. Garín, V. Pons (coms.). La gloria del barroco (pp. 319-348). Valencia: Generalitat Valenciana.

Pons, F. (2003). Erasmistas, mecenas y humanistas en la cultura valenciana de la primera mitad del siglo XVI. Valencia: Institució Alfons el Magnànim-IVEI.

Pons, F. (2005). Vespres de mort a Gandia (1500-1550). Gandia: CEIC Alfons el Vell.

Pons, V. (2005). Cardenales y prelados de Xàtiva en la época de los Borja. Xàtiva: Església Col-legial Basílica de Santa Maria-Centre d’Estudis Borgians.

Pons, V. y Cárcel, M. M. (2005). Los canónigos de la catedral de Valencia (13751520). Aproximación a su prosopografía. Anuario de Estudios Medievales, 35(2), 907-950.

Pons, V. y Muñoz, M. C. (2006). La nueva nobleza valenciana. El ejemplo de los Vich. En V. Pons, M. C. Muñoz, E. Callado (coords.). L’Ambaixador Vich. L'home i el seu temps (pp. 43-91). València: Generalitat Valenciana.

Pons, V., Muñoz, M. C., y Callado, E. (coords.) (2006). L’Ambaixador Vich. L'home i el seu temps. València: Generalitat Valenciana.

Rausell, H. (2001). Letras y fe. Erasmo en la Valencia del Renacimiento. Valencia: Diputació de València.

Serra, A. (2009). Arquitectura y urbanismo (siglos XIII-XV). En J. Hermosilla (dir.). Historia, Geografía y Arte de la ciudad de Valencia, t. 2. Valencia: Universitat de València.

Toló, E. (2015). El Mestre de Sixena i el Mestre d'Alzira: dos enigmes de la pintura del Renaixement, tesis doctoral, 3 vols. Lleida: Universitat de Lleida-Departament d'Història de l'Art i Història Social.

Ynduráin, D. (1994). Humanismo y Renacimiento en España. Madrid: Cátedra. 